\title{
Las oraciones concesivas en español y la factualidad ${ }^{1}$
}

\section{Concessives sentences and factuality in Spanish}

\author{
LEYRE BARRIOS VICENTEa \\ GLÒRIA VÁZQUEZ GARCÍAa
}

\author{
${ }^{a}$ Universitat de Lleida, Factultat de Lletres. España. \\ Correos electrónicos: leyre.barrios@udl.cat,gloria.vazquez@udl.cat
}

Cuando describimos una situación (un evento o un estado) expresamos el grado de certeza (factualidad) que le asociamos, pudiéndola presentar como cierta, incierta (probable o posible) o como no cierta. Para ello, empleamos diferentes marcadores lingüísticos. En este artículo se analiza el valor factual de las oraciones concesivas en español procedentes del registro periodístico. Este tipo de oraciones subordinadas describen una situación que se interpreta como un obstáculo no suficiente para la realización de la situación descrita en la oración principal. Nuestra hipótesis es que es posible determinar los diferentes tipos de factualidad expresados en las oraciones concesivas a partir del análisis de los conectores y tiempos verbales presentes en ellas. En este artículo proponemos reglas de anotación de la factualidad para este tipo de oraciones susceptibles de ser usadas en una herramienta automática de anotación en el marco del proyecto TAGFACT.

Palabras claves: factualidad, anotación de corpus, concesividad, modo verbal, conectores.

When we describe a situation (an event or a state), we express the degree of certainty (factuality) that we associate with it, which may be presented as true, uncertain (probable or possible) or not true. To do this, we use different types of linguistic markers. In this work, we analyse the factual value of concessive Spanish clauses of journalistic register. These subordinate sentences present a situation which is interpreted as an obstacle which is not sufficient to realise the situation described in the main clause. Our hypothesis is that it is possible to determine the different types of factuality in concessive clauses taking into account connectors and verbal tenses. In this article we also propose rules for the annotation of factuality in concessive clauses to be used in the automatic tool created as part of the TAGFACT project.

Key words: factuality, corpus annotation, concessive clause, verbal mode, linkers.

\footnotetext{
${ }^{1}$ Esta investigación se ha desarrollado en el proyecto TAGFACT: del texto al conocimiento FFI2017-84008-P (Ministerio de Economía, Industria y Competitividad). Asimismo, Leyre Barrios Vicente ha contado con la financiación de la beca de ayuda UdL, Jade Plus y la Fundación Bancaria Caixa.
} 


\section{INTRODUCCIÓN}

La interpretación de la factualidad de un evento está muy condicionada por el modo en que es presentado, es decir, por el grado de certeza que otorgue el emisor de lo narrado a la ocurrencia de dicho evento. En los últimos años se ha puesto especial interés en determinar la factualidad que se expresa en los textos y existen corpus para diferentes lenguas, especialmente el inglés, en los que se anota esta información (FactBank (2009), MEANTIME (2016)). También se han desarrollado algunas herramientas automáticas de anotación para distintas lenguas (Diab et al. (2009) y Saurí (2008) para el inglés y Wonsever et al. (2016) para el espańol). En el proyecto TAGFACT (Alonso et al. 2018; Fernández M. et al. 2020; Vázquez G. y Fernández M. 2020) se está elaborando una herramienta de este tipo para el español y este trabajo se enmarca en dicho proyecto, contribuyendo a su objetivo de analizar y automatizar la interpretación de la factualidad en español. Concretamente, en este artículo nos centraremos en analizar la factualidad en las oraciones concesivas de textos extraídos de noticias.

Cuando hablamos y describimos una situación empleamos diferentes marcadores lingüísticos que nos aportan información respecto a la certeza (o factualidad) que expresamos sobre dicha situación. Así pues, nuestra hipótesis de partida es que es posible formalizar la factualidad en las oraciones concesivas del español usando marcadores lingüísticos. Pretendemos identificar cuáles son para llegar a formalizar reglas basadas en dichos marcadores que puedan ser usadas en la herramienta automática en construcción.

La base de nuestro trabajo es la descripción que lleva a cabo Flamenco García (1999) sobre las oraciones concesivas y su valor factual. Este autor describe los tipos de concesivas en español en función de dicho valor analizando los tiempos verbales que se emplean y en función del conector que las introduce. De su trabajo se desprende que hay conectores que aportan un valor específico a la concesiva y otros que no, es decir, que pueden introducir oraciones con distintos valores factuales. Además, concluye que la mayoría de los tiempos verbales tienen asociado un único valor de factualidad, excepto en cuatro casos. Nuestras aportaciones en este campo son básicamente dos: hemos comprobado con datos empíricos extraídos de corpus lo que afirma este autor y hemos matizado algunas de sus afirmaciones a partir del análisis de dichos datos. Nuestra tercera aportación es una propuesta de reglas formales basadas en marcadores lingüísticos para anotar automáticamente la factualidad de las oraciones concesivas.

Este trabajo se estructura en cinco apartados. En el apartado 2 se presentarán las características de las oraciones concesivas, así como las distintas clasificaciones que se han propuesto en función de su factualidad. En el apartado 3 se describirá la metodología que se ha seguido para el estudio de este tipo de oraciones y la propuesta de las reglas de formalización. En el apartado 4 se presentarán los resultados obtenidos, así como dichas reglas, y, por último, en el apartado 5 se presentarán las conclusiones. 


\section{LAS ORACIONES CONCESIVAS}

En este apartado se detallarán las diferentes características de las oraciones concesivas. En primer lugar, se describen sus propiedades semánticas, en segundo lugar, las formales y, en tercer lugar, las relaciones existentes entre el modo verbal de la prótasis y el carácter factual de esta. Por último, se presentará la relación entre los distintos conectores concesivos y la factualidad.

\subsection{Propiedades semánticas}

Las oraciones concesivas han sido definidas por la tradición gramatical como aquellas en las que en la subordinada se presenta una situación que se interpreta como obstáculo que no es suficiente para la realización de la situación reflejada en la apódosis (Rivarola 1976; König 1986; Alarcos 1994; Flamenco García 1999; RAE 2010). Así, en una oración causativa como (1a), el evento de salir a correr no se cumple debido al evento de llover, ya que este se concibe como un obstáculo para su realización. Ahora bien, al introducir un conector concesivo como aunque en la oración, el significado de la oración cambia (1b), ya que el evento de la apódosis (salir a correr) se cumple a pesar de que el evento de la prótasis (llover) supone un obstáculo para su realización, ya que dicho obstáculo es superable.

\section{(1)}

a. María no salió a correr porque llovía.

b. Aunque llovía, María salió a correr.

Desde un punto de vista semántico, por tanto, en este tipo de oraciones complejas se expresa un contraste entre los eventos denotados por la apódosis y la prótasis de la oración. Como hemos visto en el ejemplo (1b), los contenidos de la apódosis y de la prótasis conducen a conclusiones contrarias, rompiendo así la relación lógica (implicativa) entre las dos situaciones denotadas. Esta cancelación produce un valor de contraexpectativa (Rivarola 1976; Rivas 1990; Cortés Parazuelos 1993; Flamenco García 1999). Este contraste que se produce al introducir aunque en la subordinada ha sido denominado por distintos autores (Cortés Parazuelos 2002; Flamenco García 1999; Pérez Saldanya y Salvador 2015; Rodríguez Rosique 2008) como 'causa ineficiente' o 'inoperante', ya que no impide la realización del evento descrito en la apódosis.

Estas nociones de contraste que subyacen a las oraciones concesivas hacen que estas estén en relación con otras oraciones, como las adversativas y un subtipo de oraciones condicionales. En cuanto a su relación con las condicionales, ambas estructuras convergen en las denominadas concesivo-condicionales escalares (2), en cuyas prótasis se hace referencia a una condición que se encuentra en el extremo de la escala y que, a su vez, es una causa ineficiente, siempre de carácter hipotético. 
(2)

Incluso si hay temporal, Antonio sale a pescar. (Flamenco García 1999: 3843).

En cuanto a su relación con las oraciones adversativas, estas son las más cercanas a las concesivas debido a que ambas comparten muy claramente la noción de contraste. En una oración como (3a) se deduce que, si alguien está enfermo, no va a trabajar. Sin embargo, al introducir en la oración pero (3b) o aunque (3c), se cancela dicha inferencia y se produce el efecto contrario al esperado.

(3)

a. Pepe estuvo muy enfermo y no fue a trabajar. (Flamenco García 1999: 3824).

b. Pepe estuvo muy enfermo, pero fue a trabajar. (Flamenco García 1999: 3813).

c. Aunque Pepe estuvo muy enfermo, fue a trabajar. (Flamenco García 1999: 3813).

No obstante, esta inferencia cancelada se presenta de diferente forma en ambas estructuras. Mientras que aunque introduce a la oración que expresa una causa inoperante, pero introduce la inferencia cancelada.

\subsection{Propiedades formales}

Desde una perspectiva sintáctica, las concesivas han sido definidas de diferentes formas. La gramática tradicional las consideraba oraciones subordinadas y las incluía dentro de las adverbiales (RAE 1973; Gili Gaya 1961). Sin embargo, estudios más recientes, como Flamenco García (1999) o RAE (2010), las sitúan dentro de las oraciones interordinadas, también denominadas bipolares, debido a su estructura bimembre y la relación semántica que mantienen la subordinada y la principal.

Sintácticamente, Flamenco García (1999) distingue entre concesivas propias e impropias. Las concesivas propias son aquellas en las que aparece el empleo de una conjunción con valor concesivo como aunque, aun cuando, si bien, pese a, etc. En cambio, las impropias son aquellas estructuras en las que no se usan dichas conjunciones, pero pueden adquirir un significado concesivo en función del contexto. Las concesivas impropias pueden ser de dos tipos: concesivo-condicionales $(2,4 \mathrm{a}, 4 \mathrm{~b})$ y paratácticas (4c), que son aquellas oraciones copulativas entre cuyos eventos denotados existe un contraste. En este estudio nos centraremos exclusivamente en analizar las concesivas propias que incluyan, además, formas verbales.

(4)

a. Este chico, vaya donde vaya, siempre hará amistades. (Flamenco García 1999: 3847).

b. Si le agrada como si no le agrada, pienso comprarme este abrigo. (Flamenco García 1999: 3846). 
c. Toca estupendamente el piano $¥$ no sabe una nota de la partitura. (Flamenco García 1999: 3849).

\subsection{Las formas verbales y la factualidad}

En este apartado vamos a presentar las distintas aportaciones realizadas por los distintos autores en relación a los tiempos verbales y la factualidad en las oraciones concesivas. Al final se presenta el cuadro 1 , donde se reflejan de forma conjunta las distintas aportaciones de cada autor y a la vez se usan mecanismos formales para diferenciarlas según la fuente. En cuanto a la terminología, en dicho cuadro se utiliza la de Flamenco García (1999), pero también se indica, entre paréntesis, la empleada por Rivas (1990) y Borrego et al. (1985), que son los autores que han hecho las aportaciones más importantes en este campo.

Las oraciones concesivas pueden aparecer tanto con indicativo como con subjuntivo en función de distintos factores: el carácter informativo y la factualidad del contenido expresado (Borrego et al. 1985; Flamenco García 1999). En este trabajo nos centraremos en el segundo aspecto, ya que el primero va más allá del tema que nos ocupa. A este respecto, autores como Gili Gaya (1961) defienden la existencia de una oposición modal que se basa en el carácter real o posible de la prótasis de la concesiva. Cuando la subordinada se halla en indicativo, el evento es real (5a), y cuando se halla en subjuntivo, el evento es posible, usando la terminología de este autor (5b). Esta dicotomía está representada en el cuadro 1 en las casillas en blanco y con negrita y se usan los términos factual y semifactual, respectivamente.

(5)

a. Aunque hace mal tiempo, saldré. (Gili Gaya 1961: 323).

b. Aunque haga mal tiempo, saldré. (Gili Gaya 1961: 322).

Cabe decir, no obstante, que en español es posible también usar construcciones concesivas con subjuntivo (concretamente, el presente) para describir situaciones reales. El primer autor en identificar este uso fue Vallejo (1922), quien lo denominó subjuntivo polémico. Dichas situaciones son previamente presentadas en la conversación por un hablante A y son replicadas por el hablante B con el uso de una concesiva en la que se reafirma la veracidad. Como indica Flamenco García (1999), en estos casos el presente de subjuntivo puede ser sustituido por el presente de indicativo sin alterar el significado del enunciado (6). En el cuadro 1, esta aportación de Vallejo se refleja con el color gris claro y se usa el término factual.

(6)

A: No salgas, está diluviando.

B: Pues aunque $\{e s t e ́ l e s t a ́\}$ diluviando, tengo que acudir a la reunión. (Flamenco García 1999: 3826). 
Esta cuestión es muy relevante en nuestro estudio, ya que, para conseguir nuestro objetivo y encontrar pistas formales que nos permitan determinar la factualidad de una oración, va a ser crucial detectar qué tiempos verbales tienen siempre la misma interpretación factual y cuáles pueden recibir distintos valores de factualidad según la frase. En este último caso, siempre que sea posible, habrá que localizar otros rasgos que ayuden a determinar dicha interpretación. Así pues, el presente de subjuntivo sería un primer caso de tiempo verbal detectado al cual se le pueden asociar dos valores respecto a la certeza: semifactual, o sea, incierto (5b), y factual o cierto (6).

Siguiendo la clasificación de Gili Gaya, autores como Rivas (1990) y Borrego et al. (1985) realizan una nueva propuesta que incluye, a grandes rasgos, dos innovaciones. En el cuadro 1, estas innovaciones están señaladas en las casillas en blanco y sin negrita. Los términos que aparecen entre paréntesis en estas casillas son los usados por estos autores.

En primer lugar, añaden una tercera oposición modal que se basa en la noción de irrealidad. La irrealidad hace referencia a situaciones imposibles (no ciertas), ya que no han tenido lugar en el pasado ni tienen lugar en el presente (contrafactualidad). En este tipo de concesiva se usan las formas del pretérito imperfecto de subjuntivo para referirse a una situación del presente que no ha sucedido (7a), y del pretérito pluscuamperfecto de subjuntivo para una situación del pasado que tampoco ha ocurrido (7b).

(7)

a. CARMEN: Está lloviendo a mares.

ENRIQUE: A mí me da igual, porque aunque ahora mismo hiciera buen tiempo, yo no me movería de casa. (Borrego et al. 1985: 168).

b. CARMEN: Ayer llovió a mares.

ENRIQUE: A mí me da igual, porque aunque hubiera hecho buen tiempo, yo no me habría movido de casa. (Borrego et al. 1985: 168).

En segundo lugar, estos autores indican, como también puede observarse en la misma tabla (columna "Probabilidad"), que en los casos de situaciones semifactuales (o hipotéticas, usando su terminología) los tiempos de subjuntivo varían en función del grado de probabilidad que se les otorgue a dichas situaciones. Así, si el hablante considera la situación descrita en la prótasis como probable, empleará el presente de subjuntivo para referirse al presente y el futuro (8a) o el pretérito perfecto o imperfecto para referirse al pasado (8b). En cambio, si la considera de realización improbable, empleará las formas del pretérito imperfecto para describir situaciones del presente o el futuro (8c) y las formas del pretérito pluscuamperfecto para las referidas al pasado (8d).

a. (En la cama, antes de levantarse, con la persiana bajada) Aunque ahora mismo haga buen tiempo, yo no me muevo de la cama. (Borrego et al. 1985: 167). 
b. Aunque esta mañana haya hecho buen tiempo (y yo lo ignoro, porque todavía no me he levantado de la cama), no me he movido de casa. (Borrego et al. 1985: 167).

c. Aunque mañana hiciera buen tiempo (pero lo dudo, porque no para de llover), no me movería de casa. (Borrego et al. 1985: 167).

d. Aunque esta mañana / ayer hubiera hecho buen tiempo (y yo lo ignoro, pero lo dudo, porque lleva quince días lloviendo), no me habría movido de casa. (Borrego et al. 1985: 167).

Como puede deducirse de lo expuesto, se identifican dos tiempos más del subjuntivo a los cuales se puede asociar más de un valor de factualidad: por un lado, el pretérito imperfecto de subjuntivo y, por otro, el pretérito pluscuamperfecto de subjuntivo. Ambos pueden usarse en contextos semifactuales o hipotéticos (8c, 8d) y contrafactuales o irreales (7a, 7b).

Otra clasificación sobre la factualidad de las concesivas es la de Flamenco García (1999). Manteniendo la línea anterior, para este autor las concesivas propias pueden ser factuales, semifactuales y contrafactuales, equivalentes a las que Rivas (1990) y Borrego et al. (1985) denominaban reales, hipotéticas e irreales, respectivamente. Lo novedoso de esta clasificación es que, remitiendo a la teoría de los tiempos dislocados de Rojo (1974), se aúnan las funciones modales con los tiempos verbales. Según esta teoría, el sistema modal del verbo español se compone de cinco funciones modales: indicativo 0 (IND 0), indicativo 1 (IND 1), indicativo 2 (IND 2), subjuntivo 0 (SUBJ 0) y subjuntivo 2 (SUBJ 2).

IND 0 y SUBJ 0 se corresponden con situaciones factuales. Cabe destacar que, tal como expone este autor, el futuro simple y el compuesto pueden tener una interpretación factual (9a), asociada a IND 0, pero también semifactual, recogida en IND 1. Concretamente, en cuanto a los usos semifactuales, IND 1 recoge los de futuro y condicional (junto con sus formas compuestas) (9b, 9c). Además, el autor vincula los tiempos de subjuntivo del cuadro 1 asociados a este valor (semifactual) con una nueva función modal (SUBJ 1).

(9)

a. Aunque recibiré el dinero esta tarde, no me lo gastaré. / Aunque antes de las tres ya habré recibido el dinero, no lo ingresaré en el banco hasta mañana. (Flamenco García 1999: 3828/9).

b. Aunque ahora estará en su cuarto, no debemos molestarle. / Aunque aún no habrá terminado de estudiar, voy a saludarle. (Flamenco García 1999: 3830).

c. Aunque ayer seguiría enfermo, siguió trabajando. / Aunque ya entonces habrían vuelto de vacaciones, no les llamé. (Flamenco García 1999: 3830).

Por último, respecto a las oraciones concesivas con interpretación de irrealidad, este autor vincula los tiempos de subjuntivo del cuadro 1 asociados a este valor factual con la función modal SUBJ 2. Asimismo, este autor emplea la función IND 2 para denominar a las formas del indicativo que también se refieren a situaciones irreales. En estos casos, el 
hablante usará las formas simples y compuestas de condicional (10) en función de si se refiere al presente o al pasado, respectivamente.

Aunque de buena gana viviría en París, no se está tan mal aquí en Madrid. I Aunque le habría ayudado gustosamente, preferí mantenerme al margen para evitar comentarios. (Flamenco García, 1999: 3832).

A partir de las aportaciones de Flamenco García (1999) observamos que, además de las formas verbales del subjuntivo (presente, pretérito imperfecto y pretérito pluscuamperfecto), existen otras dos que pueden tener más de una interpretación factual, y en este caso pertenecen al modo indicativo: el futuro y el condicional y sus formas compuestas. Por un lado, las dos formas de futuro pueden emplearse en la prótasis de las oraciones concesivas tanto para eventos factuales (9a) como semifactuales (9b). Por otro, las dos formas de condicional pueden aparecer introduciendo eventos tanto semifactuales (9c) como contrafactuales (10).

Cuadro 1. Recopilación de la Interpretación factual de los tiempos verbales usados en las oraciones concesivas según la bibliografía

\begin{tabular}{|c|c|c|c|c|c|}
\hline Modo & Factualidad & $\begin{array}{c}\text { Función } \\
\text { modal }\end{array}$ & Probabilidad & $\begin{array}{l}\text { Tiempo de } \\
\text { referencia }\end{array}$ & $\begin{array}{l}\text { Tiempo } \\
\text { verbal }\end{array}$ \\
\hline \multirow{5}{*}{ 芑 } & Factual (real) & IND 0 & ---- & --- & Todos \\
\hline & \multirow{2}{*}{$\begin{array}{l}\text { Semifactual } \\
\text { (hipotética) }\end{array}$} & \multirow{2}{*}{ IND 1} & \multirow{2}{*}{ Probable } & Presente & $\begin{array}{c}\text { Futuro / Futuro } \\
\text { compuesto }\end{array}$ \\
\hline & & & & Pasado & $\begin{array}{l}\text { Condicional simple / } \\
\text { Condicional compuesto }\end{array}$ \\
\hline & \multirow{2}{*}{$\begin{array}{l}\text { Contrafactual } \\
\text { (irreal) }\end{array}$} & \multirow{2}{*}{ IND 2} & ---- & Presente & Condicional simple \\
\hline & & & ---- & Pasado & Condicional compuesto \\
\hline \multirow{7}{*}{ 苞 } & Factual (real) & SUBJ 0 & --.- & ---- & Presente \\
\hline & \multirow{4}{*}{$\begin{array}{l}\text { Semifactual } \\
\text { (hipotética) }\end{array}$} & \multirow{4}{*}{ SUBJ 1} & \multirow{2}{*}{ Probable } & $\begin{array}{l}\text { Presente / } \\
\text { Futuro }\end{array}$ & Presente \\
\hline & & & & Pasado & $\begin{array}{l}\text { Pretérito Perfecto o } \\
\text { Imperfecto }\end{array}$ \\
\hline & & & \multirow{2}{*}{ Improbable } & $\begin{array}{l}\text { Presente / } \\
\text { Futuro }\end{array}$ & Pretérito Imperfecto \\
\hline & & & & Pasado & $\begin{array}{c}\text { Pretérito } \\
\text { Pluscuamperfecto }\end{array}$ \\
\hline & \multirow{2}{*}{$\begin{array}{l}\text { Contrafactual } \\
\quad \text { (irreal) }\end{array}$} & \multirow{2}{*}{ SUBJ 2} & \multirow{2}{*}{----} & Presente & Pretérito Imperfecto \\
\hline & & & & Pasado & Pretérito Pluscuamperfecto \\
\hline
\end{tabular}


En conclusión, aunque, a partir de lo expuesto, se ha observado que se establecen correspondencias claras entre los tiempos verbales y los valores factuales, hay algunas formas verbales no concluyentes. Además de las del subjuntivo ya mencionadas, que son el presente, el pretérito imperfecto y el pretérito pluscuamperfecto, existen otras dos en indicativo: el futuro y el condicional. Por un lado, el futuro puede emplearse en la prótasis tanto para eventos factuales como semifactuales. Por otro, el condicional puede aparecer introduciendo eventos tanto semifactuales como contrafactuales.

\subsection{Formas no finitas y factualidad}

Flamenco García (1999) recoge asimismo el empleo de formas no finitas, adjetivos y adverbios en las prótasis concesivas. El infinitivo, cuyo carácter es siempre factual, se construye precedido por para (11a) o por con (11b).

\section{(11)}

a. Para haber estado en la playa tanto tiempo, no se puso muy moreno. (Flamenco García 1999: 3851).

b. Estas explicaciones, con ser muchas de ellas valiosas, no abarcan la totalidad del fenómeno religioso, al que tienden siempre a reducir y minimizar. (Flamenco García 1999: 3852).

El gerundio aparece siempre introducido por la partícula aun y puede presentar los tres valores factuales. Cuando en la apódosis hay un tiempo de pasado, presente o futuro, la oración es factual (12a). Si, en cambio, hay una forma de futuro o condicional simple y un gerundio simple en la prótasis, la concesiva se considera semifactual (12b). Si hay un condicional simple o compuesto y en la prótasis un gerundio compuesto, la concesiva es contrafactual (12c).

(12)

a. Aun pegándole, no vas a conseguir que te obedezca. (Flamenco García 1999: 3853).

b. Aun comiendo mucho, no \{engordarán/engordarían\}. (Flamenco García 1999: 3854).

c. Aun habiendo comido mucho, no habrían engordado. (Flamenco García 1999: 3854).

En cuanto a las concesivas con participio, esta categoría puede venir introducida por un conector concesivo como aunque o si bien. Cuando en la apódosis hay un tiempo de presente o pasado, la concesiva se considera factual (13a). En cambio, si hay un condicional, la concesiva es semifactual (13b), si bien el autor lo considera anómalo. 
(13)

a. La ley, aunque aprobada por la mayoría, no \{pudo/puede/podrá\} salir adelante. (Flamenco García 1999: 3854).

b. ${ }^{*} E l$ presidente, si bien odiado por todos, \{seguiría/habría seguido\} mandando. (Flamenco García 1999: 3854).

\subsection{Conectores y factualidad}

La mayoría de los estudios de la concesividad en español se centran en el empleo de la conjunción aunque, puesto que es la más frecuente. No obstante, es común encontrar otras conjunciones o conectores para expresar esta noción. Es el caso de aun cuando, si bien, a pesar de (que), etc.

Flamenco García (1999) es quien hace un análisis más detallado sobre los distintos conectores concesivos y su valor factual. Según este autor, podemos agruparlos en cuatro grupos en función de su factualidad: los que introducen situaciones factuales, los que introducen situaciones hipotéticas o contrafactuales y los que pueden presentar más de un valor factual (cuadro 2).

Cuadro 2. Clasificación de los conectores en función de su valor factual (Flamenco García 1999)

\begin{tabular}{|c|c|c|c|}
\hline Factuales & $\begin{array}{c}\text { Semifactuales } \\
\text { (hipotéticos) }\end{array}$ & $\begin{array}{c}\text { Contrafactuales } \\
\text { (irreales) }\end{array}$ & $\begin{array}{c}\text { Todos los valores } \\
\text { factuales }\end{array}$ \\
\hline si bien & Así & Así & Aunque \\
\hline y eso que & Siquiera & & aun cuando \\
\hline (aun) a sabiendas de (que) & (aun) a riesgo de (que) & & a pesar de (que) \\
\hline con... que & & & por más que \\
\hline Tan(to)... como & & & por mucho que \\
\hline pese a (que) & & & por + adj./ adv. que \\
\hline
\end{tabular}

Como conectores factuales, Flamenco García incluye si bien (14a), y eso que (14b), (aun) a sabiendas de (que) (14c), con... que (14d), tan(to)... como (14e) y pese a (que) (14f).

a. Se enfocará positivamente el tema de la integración europea, si bien parece ser que el primer ministro no abandonará sus críticas a la idea de la moneda única. (Flamenco García 1999: 3834). 
b. No he conseguido entradas para la ópera, y eso que hice cola durante más de dos horas. (Flamenco García 1999: 3834).

c. Nos dejaron solos aun a sabiendas de que nos perderíamos. (Flamenco García 1999: 3836).

d. Juan, con lo formal que parecía, siempre estaba de juerga. (Flamenco García 1999: 3839).

e. ¡Tan tarde como es y no se molesta en llamar a su familia! (Flamenco García 1999: 3840).

f. El estreno ha sido un fracaso, pese a que se preveía una gran asistencia de público. (Flamenco García 1999: 3835).

Dentro de los conectores semifactuales se encuentran (aun) a riesgo de que (15a), siquiera (15b) y asi (15c). Este último conector, según Flamenco García, también puede ser contrafactual (15d), aunque ya hemos visto que no solo presenta este valor.

a. La invité a la fiesta a riesgo de que \{organizara/*organizó\} un escándalo. / Está tuteando a su jefe, aun a riesgo de que le $\left\{\right.$ moleste $/{ }^{*}$ molesta $\}$. (Flamenco García 1999: 3836).

b. Merece ser castigado, siquiera sealfuera otro el cerebro del crimen. (Flamenco García 1999: 3834).

c. Esta prueba, así sea fundamental, no sirve para la acusación porque se ha obtenido por medios ilícitos. (Flamenco García 1999: 3834).

d. Así lloviera a mares, no por eso dejaría de haber restricciones. (Flamenco García 1999: 3833).

El resto de conectores concesivos no son concluyentes en cuanto a la factualidad, ya que pueden presentar varios valores factuales en función del modo y tiempo verbal con el que aparezcan. A continuación, vamos a ejemplificar un valor factual y otro semifactual para cada uno de estos conectores (16).

a. Aunque ahora está lloviendo, iremos al campo. / Aunque llegasen a un acuerdo en la reunión de la semana pasada, dato que aún está por confirmar, las posibilidades de ruptura en el partido parecen acrecentarse día a día. (Flamenco García 1999: 3828/3831).

b. Aun cuando Pepe dice tonterías, es un chico brillante. / Me quedaré hasta muy tarde aun cuando seguramente lo lamentaré (Flamenco García 1999: 3833).

c. A pesar de que me he tomado ya varias pastillas, no siento ninguna mejoría. I - A: Según parece, esta vez no van a ganar los socialistas. - B: Pues, 
a pesar de que se $\{$ diceldiga $\}$ eso, ya verás cómo remontan en el último momento. (Flamenco García 1999: 3835).

d. - A: Ten cuidado con este. Sabe muchas cosas. - B: Pues por mucho que sepa, a mí no me va a acomplejar. / Por muchos libros que $\{$ lea /*lee\}, nunca será un genio (Flamenco García 1999: 3837).

e. - A: ¿Por qué no lo compras? ... ya sabes que es muy práctico. - B: Ya, pero por muy práctico que sea, es demasiado caro. / Esa propuesta, por extraña que te parezca, es muy interesante. (Flamenco García 1999: 3838).

f. Por más libros que leyera, no conseguiría dar con la solución. / Por más libros que lee, no consigue dar con la solución. (Flamenco García 1999: 3836/3837).

\section{Metodología}

Para la realización de este trabajo se han obtenido datos de corpus que recogen el empleo del español actual en el registro periodístico. Concretamente, se ha creado un corpus compuesto por 973 oraciones concesivas; todas ellas incluyen formas verbales en la prótasis (no adjetivales ni adverbiales ni nominales) y pertenecen al discurso periodístico. Consideramos que se trata de una cantidad suficientemente representativa para poder extraer conclusiones.

Para la recopilación de oraciones se han usado el subcorpus periodístico del Corpus del Español del Siglo XXI (CORPES XXI) y el corpus NOW del Corpus del Español de Mark Davies, así como diferentes artículos periodísticos procedentes de periódicos españoles consultados en línea (El Mundo, Público, eldiario.es, etc.). Su temática abarca principalmente la política, el deporte, la justicia y la economía.

Para establecer el grado de factualidad de las oraciones concesivas, se han usado cuatro etiquetas: "factual", cuando el evento de la prótasis hace referencia a un evento que acontece o ha acontecido; "no factual", cuando presenta cierto grado de incerteza o probabilidad; "contrafactual", cuando hace referencia a un evento que no ocurre o que no ha ocurrido; y "no aplica" cuando hace referencia a un mundo imaginado proyectado al futuro y presentado como un deseo, una obligación o una situación planteada como hipotética. La clasificación usada en este trabajo está en consonancia con la mayoría de propuestas en el ámbito de la anotación de la factualidad (Saurí 2008; Wonsever et al. 2016). A continuación, presentamos la correspondencia de estas etiquetas con las mencionadas en el apartado 2:

- Factual: real

- No factual: semifactual, hipotética

- Contrafactual: irreal

- No aplica: semifactual, hipotética 
Los marcadores lingüísticos que se han usado para determinar la factualidad de las concesivas son los ya mencionados: los conectores y los tiempos verbales. Además, para las oraciones con conectores y tiempos verbales no concluyentes, se ha usado otro marcador, el tiempo de la apódosis.

Se ha pretendido garantizar que todos los conectores y todos los tiempos verbales de la prótasis tengan representación, por lo que se han realizado búsquedas con todos ellos. Hay que señalar que en los corpus de noticias consultados no se han encontrado seis de los conectores concesivos (y eso que, con... que, tan(to)... como, así, siquiera y por (muy) $+\mathrm{ADV}+q u e)$, por lo que deducimos que no son propios del lenguaje periodístico. En definitiva, de todo el conjunto de oraciones recopiladas y analizadas, 329 están introducidas por aunque, mientras que para el resto de conectores hemos considerado entre 50 y 90 oraciones para cada uno. La diferencia numérica se debe a que aunque es la conjunción concesiva prototípica y, por tanto, la más común.

Por lo que respecta a los tiempos verbales propios de las oraciones concesivas, se han obtenido ejemplos de todos los tiempos de indicativo y subjuntivo (cuadro 3). Los tiempos verbales más frecuentes son el presente y el pretérito perfecto simple de indicativo y el presente de subjuntivo, por lo que las frases analizadas con estos tiempos son más de 100 en cada caso, mientras que para el resto de tiempos verbales el estudio se ha realizado con un número de frases que oscila entre 24 y 55.

Cuadro 3. Casos obtenidos de cada tiempo verbal

\begin{tabular}{|l|c|c|}
\hline \multirow{4}{*}{ Modo verbal } & Tiempo Verbal & Número de casos \\
\hline \multirow{4}{*}{ INDICATIVO } & Presente & 171 \\
\cline { 2 - 3 } & Pretérito imperfecto & 43 \\
\cline { 2 - 3 } & Pretérito perfecto simple & 111 \\
\cline { 2 - 3 } & Pretérito perfecto compuesto & 55 \\
\cline { 2 - 3 } & Pretérito pluscuamperfecto & 30 \\
\cline { 2 - 3 } & Futuro simple & 25 \\
\cline { 2 - 3 } & Condicional simple & 46 \\
\cline { 2 - 3 } & Condicional compuesto & 24 \\
\hline \multirow{5}{*}{ SUBJUNTIVO } & Presente & 182 \\
\cline { 2 - 3 } & Pretérito imperfecto & 52 \\
\cline { 2 - 3 } & Pretérito perfecto & 27 \\
\cline { 2 - 3 } & Pretérito pluscuamperfecto & 43 \\
\hline
\end{tabular}


En cuanto a las formas no finitas, se han obtenido también ejemplos de todas ellas (cuadro 4). Los ejemplos estudiados para estas formas no verbales oscilan entre 21 y 63 , siendo la más baja la correspondiente a los participios.

Cuadro 4. Casos obtenidos de cada forma no finita

\begin{tabular}{|c|c|}
\hline Forma no finita & Número de casos \\
\hline Infinitivo & 60 \\
\hline Gerundio & 63 \\
\hline Participio & 21 \\
\hline
\end{tabular}

Hemos establecido 3 fases en el análisis de las oraciones. El orden de las fases se ha estipulado teniendo en cuenta que el estudio se enmarca en el proyecto TAGFACT, en el que se pretende crear una herramienta automática para anotar la factualidad de las oraciones.

En primer lugar, se han analizado las frases recopiladas para comprobar la validez del valor factual de los distintos conectores concesivos señalados por Flamenco García (1999). En segundo lugar, si el conector resulta ser no concluyente, es decir, si presenta dos o más valores factuales, se ha comprobado si la previsión del valor factual de los tiempos verbales de la prótasis que este autor propone concuerda con el análisis de nuestro corpus. En tercer lugar, si ni el conector ni el tiempo verbal de la prótasis determina el valor factual de la oración porque estos pueden presentar diversos valores factuales, se tiene en cuenta el tiempo verbal de la apódosis. Aplicando esta metodología el valor factual de todas las oraciones, ha podido ser determinado a través de los marcadores lingüísticos excepto aquellas con condicional en la prótasis, ha sido adjudicada.

Para finalizar, queremos aclarar que, en el grupo de las 973 concesivas estudiadas no se han contabilizado algunas oraciones. Es el caso de aquellas que presentan omisión verbal en la prótasis (17a) o que presentan una sintaxis complicada (p.e., mucha subordinación) (17b). Este tipo de oraciones supone un reto que no está resuelto y que dejamos también como línea futura de investigación.

También se han descartado de este estudio aquellas oraciones que presentan o bien en la prótasis o bien en la apódosis una perífrasis verbal (17c), ya que estos casos son tratados con sus propias reglas en el proyecto.

a. Mientras el Gobierno de Zimbabue asegura que falleció a bordo del avión (...), desde la nación vecina se asegura que está aún con vida, aunque $\varnothing$ en estado crítico. (CORPES XXI). 
b. Las fuentes de Cs consultadas aseguran que (...), y aun reconociendo que "no es sencillo", cabría la posibilidad de hacer un "esfuerzo de comunicación" (...). (Corpus del Español). ${ }^{2}$

c. El escrutinio oficial (...) vuelve a dejar una importante sorpresa (...), aunque ahora es en el caso de las elecciones autonómicas. (Corpus del Español).

Por último, se han excluido aquellas oraciones procedentes de blogs de los propios periódicos, ya que no necesariamente reflejan un registro periodístico.

\section{RESULTADOS Y DISCUSIÓN}

En este apartado se presentarán los datos obtenidos del análisis de las oraciones de los corpus con el fin de poder demostrar si nuestra hipótesis de partida es acertada o no, es decir, si es posible formalizar reglas para dar cuenta de la factualidad en las oraciones concesivas del español. Además, se presentará en qué medida nuestro análisis, fundamentado empíricamente con un número considerable de oraciones, es coincidente con el que se hace en la bibliografía. En primer lugar, se describirán cómo afectan a la factualidad de las oraciones los conectores concesivos (4.1). En segundo lugar, se presentarán los tiempos verbales de las prótasis (4.2), tanto los que determinan la oración respecto a la factualidad (4.2.1) como aquellos que son no concluyentes (4.2.2). En tercer lugar, se detallarán qué tiempos de los verbos de las apódosis permiten otorgar un valor sobre factualidad al resto de oraciones (4.3). Por último, se presentarán los patrones de formalización y los resultados globales (4.4).

\subsection{Conectores}

Por un lado, en nuestro estudio podemos decir que coincidimos con la clasificación de Flamenco García (1999) (v. ap. 2.5) en cuanto a los conectores (aun) a sabiendas de (que) (18a) y (aun) a riesgo de (que)(18b), ya que, según este autor tienen asociados valores factuales e hipotéticos, respectivamente (aunque para el segundo, lo subespecificamos como "no aplica"; v. ap. 3).

a. Allí se formó policialmente y allí se desplazaba continuamente desde su Galicia natal aun a sabiendas de que era un destino peligroso. (Corpus del Español).

\footnotetext{
${ }^{2}$ Los errores encontrados en los ejemplos del Corpus del Español, como repetición de palabras o la separación de contracciones de preposiciones seguidas de artículo, han sido corregidos en todos los ejemplos presentados en este trabajo.
} 
b. Eso explica que, tras la debacle en Andalucía, haya decidido su último giro: llevar los Presupuestos Generales del Estado (PGE) a las Cámaras, aun a riesgo de que no sean aprobados. (Corpus del Español).

Es importante señalar que (aun) a sabiendas de (que) puede ir seguido de futuro. Como veremos en el apartado 4.2.1 en nuestra propuesta, cuando este tiempo se usa para prever situaciones (19), como estas no pueden corroborarse porque no han sucedido, son etiquetadas como no factuales. No es tanto una discrepancia, sino la adopción de una visión distinta.

(19)

'Mou' intentó cortar en seco aun a sabiendas de que será una cuestión recurrente de aquí al final de la temporada. (CORPES XXI).

En cambio, sí discrepamos del análisis realizado por Flamenco García (1999) para los conectores a pesar de (que), si bien y pese a (que) (v. ap. 2.3). Este autor otorga a estos conectores un valor factual. En nuestro análisis, en cambio, estos conectores pueden variar dicho valor en función del tiempo verbal que aparezca en la prótasis de la oración (v. ap. 4.2).

El resto de conectores concesivos, es decir, aunque, aun cuando, por muy $+\mathrm{ADJ}$ + que, por más que y por mucho que, presentan distintos valores factuales tanto en nuestro análisis como en el de Flamenco García (1999). En estos casos se hace necesario recurrir al análisis del tiempo verbal de la prótasis para determinar la factualidad de la oración.

A partir de lo expuesto, presentamos una propuesta de clasificación de los conectores concesivos en función del valor factual que presenten algo modificada respecto a la de Flamenco García (1999) (cuadro 5). Como puede observarse, después de un análisis basado en corpus, la ambigüedad de los conectores respecto a los valores de factualidad que tienen asociados es mayor de lo que se había previsto.

Cuadro 5. Clasificación factual de los conectores

\begin{tabular}{|c|c|}
\hline No aplica & Varios valores factuales \\
\hline (aun) a riesgo de (que) & a pesar de (que) \\
\hline & Aunque \\
\hline & aun cuando \\
\hline & por más que \\
\hline & por mucho que \\
\hline & por muy ADJ $+q u e$ \\
\hline & pese a (que) \\
\hline & si bien \\
\hline & (aun) a sabiendas de que \\
\hline
\end{tabular}




\subsection{Tiempos verbales en la prótasis}

\subsubsection{Tiempos verbales no concluyentes}

En los casos en los que los conectores concesivos presentan distintos valores factuales, es necesario recurrir al análisis del tiempo verbal de la prótasis para determinar el carácter de certeza de la oración. Como tiempos verbales concluyentes encontramos tanto tiempos de indicativo como de subjuntivo. Asimismo, también determinan el valor de la oración las formas no finitas.

En primer lugar, en cuanto a los tiempos del indicativo, de acuerdo con lo señalado por Flamenco García (1999), los siguientes siempre serán factuales, independientemente del conector: el presente ${ }^{3}(20 \mathrm{a})$, el pretérito imperfecto (20b), el pretérito perfecto simple (20c), el pretérito perfecto compuesto (20d) y el pretérito pluscuamperfecto (20e).

a. Con esta celebración sucede lo mismo que con la de la navidad que se celebra en todo el mundo aun cuando no todo el mundo es cristiano. (Corpus del Español).

b. "La mediación no fue solicitada (...), aun cuando desde el Gobierno español y su presidente habia un deseo de mantenerse informado" (ART).

c. El argentino defendió la calidad de los fichajes del equipo, aunque lamentó que "sólo puedan jugar once en una plantilla de tanta calidad". (CORPES XXI).

d. (...), pero que por más que han intentado refutar repasando toda la metodología, no han conseguido encontrar dónde está el error. (CORPES XXI).

e. El presidente de Tussam y alcalde de Sevilla (...) fue gestor privado del Teatro Imperial de Sevilla, aun cuando habia sobrepasado en ocho meses el plazo máximo de excedencia voluntaria, (...). (CORPES XXI).

En cuanto al futuro, según Flamenco García (1999), este tiempo verbal puede expresar situaciones factuales (9a) cuando el evento esté enfocado al futuro, o no factuales (9b) cuando esté enfocado al presente. Desde nuestra perspectiva, coincidimos con el análisis realizado para (9b), pero no para (9a), ya que, aunque se presente una situación del futuro como muy segura, no sabemos con absoluta certeza si ocurrirá o no. Así pues, en nuestro trabajo, como ya hemos avanzado, si una oración expresa una acción futura, será siempre no factual (21), en la línea de lo que se ha optado en otros proyectos de anotación de la factualidad como Wonsever et al. (2016), entre otros.

\footnotetext{
${ }^{3}$ Hay que señalar que en nuestro corpus no se han encontrado oraciones de presente con referencia al futuro.
} 
(21) Del Cid resiste y gana en Torremolinos, aunque necesitará apoyos para gobernar. (Corpus del Espańol).

En cuanto al condicional compuesto, recordamos que Flamenco García (1999) considera que este tiempo verbal puede presentar eventos no factuales (9c) o contrafactuales (10) (v. ap. 2.3). No obstante, en nuestro corpus se han encontrado ejemplos con carácter contrafactual (22a), no factual (22b) y "no aplica" (22c).

a. La Fiscalía aún no ha formulado ninguna acusación contra’ El Pastelero’ y’ Costińa', a pesar de que habría tenido la oportunidad de que se les juzgase en la primera semana de enero (...). (Corpus del Español).

b. Según el sondeo (...), el Partido Conservador se haría con la victoria en los comicios, si bien habría perdido la mayoría absoluta (...). (Corpus del Español).

c. Pese a que habría bastado con acreditar el desvío de 250.000 euros (...), la Fiscalía habría conseguido justificar dos millones de euros (...). (Corpus del Español).

En segundo lugar, en el subjuntivo, coincidiendo plenamente con lo señalado por Flamenco García (1999), el pretérito perfecto determina el valor de la concesiva. Cuando aparece este tiempo verbal en la prótasis (23), el carácter de la concesiva es factual.

(23) Aunque dicho estudio se haya realizado en Madrid, es perfectamente extrapolable a bastantes cines (...). (CORPES XXI).

Por último, en cuanto a las formas no finitas, de acuerdo con Flamenco García (1999), también determinan el valor factual de la oración el infinitivo, tanto simple como compuesto, (24a) y el participio (24b). Para el gerundio, al contrario de lo señalado por el autor (v. ap. 2.3), hemos observado que esta forma no finita, ya sea en su forma simple o compuesta, siempre es de carácter factual en nuestro corpus (25). En un futuro, sería necesario ampliar el número de ejemplos estudiados con esta forma.

a. (...) Conde-Pumpido ha enviado la denuncia del Partido Socialista de Madrid (PSM) a la Fiscalía Anticorrupción "a pesar de conocer que no existen delitos (...)”. (CORPES XXI). / (...), la Comisión Europea ha desestimado sobreseer la investigación por entender que, pese a haber sido anuladas, algunas de las normas todavía tienen efecto (...). (CORPES XXI).

b. Aunque reforzado, se trata del único Ayuntamiento que conservan los socialistas en la Margen Izquierda, si bien el vencedor de la noche en la villa destacó el "refuerzo" constatado en Santurtzi y Sestao (CORPES XXI). 
(25) Aun bajando de la cota del 49\%, la caída del PSOE y la exigua subida (...) le valió a Barreiro y los suyos para mantenerse en los ocho diputados. (CORPES XXI) / El Ebitda de Cuatro mejora un 11\%, aun habiéndose registrado en 2010 los costes del Mundial de fútbol de 2010. (CORPES XXI).

\subsubsection{Tiempos verbales no concluyentes}

En nuestro estudio encontramos cinco formas finitas que presentan varios valores factuales y que, por tanto, no determinan el valor factual de la concesiva. Se trata del condicional simple y compuesto, del presente, del pretérito imperfecto y pluscuamperfecto de subjuntivo.

En cuanto al condicional simple, Flamenco García (1999) señala los mismos valores que para el condicional compuesto, es decir, puede hacer referencia a eventos no factuales (9c) o contrafactuales (10) (v. ap. 2.3). No obstante, en nuestro estudio se han encontrado ejemplos factuales con condicional simple en la prótasis (26a). Además, tanto la forma simple (26b) como la compuesta (26c) pueden recibir también el valor "no aplica".

a. Los locales recuperaron la iniciativa (...), aunque sería el Córdoba el que capitalizaría las aproximaciones (...). (Corpus del Español).

b. Si el PP, Ciudadanos y Vox no pactan entre ellos, ella repetiría como alcaldesa, aunque gobernaría en una situación de minoría. (Corpus del Español).

c. El imputado sí admitió que se firmaron peonadas falsas para acceder a el subsidio agrario a varias personas, aunque habría responsabilizado de ello a los delegados municipales de Personal y de Campo (Corpus del Español).

Respecto al subjuntivo, hemos observado a partir de los datos analizados que este presenta ambigüedades tanto en el presente $(27 \mathrm{a}, 27 \mathrm{~b})$ como en el pretérito imperfecto (28a, 28b, 28c) y pluscuamperfecto (29a, 29b, 29c). En nuestro corpus, el presente de subjuntivo puede presentar un valor factual (27a) o no factual (27b); el imperfecto puede ser factual (28a), "no aplica" (28b) o contrafactual; y el pluscuamperfecto puede presentar un valor factual (29a), contrafactual (29b) o "no aplica" (29c). El único valor añadido respecto a la propuesta de Flamenco García (1999) (v. ap. 2.3) es el factual para el pretérito pluscuamperfecto (29a), que este autor no había previsto.

a. La mayoría de los países de la UE se inclinan por estrenar ya la política de defensa europea, aunque sea por la puerta trasera (CORPES XXI).

b. Por mucho que se trague sapos y llegue a un acuerdo con Podemos (...) le haría falta el apoyo de lo que queda de IU (...). (CORPES XXI). 
(28)

a. El Barça, (...), lo dejó sin rubor, por más que fuera el fichaje más caro de su historia (...). (Corpus del Español).

b. Pese a el escándalo, estaba dispuesto a ir a Mallorca. Aun a riesgo de que se produjeran incomodas escenas, como la del domingo 15 de julio en Sanxenxo. (Corpus del Español).

c. Aunque quisiera, Inma Iruretagoiena sería incapaz de ofrecer a los suyos una explicación (...). (CORPES XXI).

a. Schrems, (...) descubrió que la plataforma guardaba los datos de los usuarios, aunque ellos los hubieran borrado. (Corpus del Español).

b. Aunque Batasuna-SA no hubiera votado, el resultado habría sido el mismo. (CORPES XXI)

c. En el caso español, cualquier "pinchazo" preventivo de la burbuja, por muy saludable que hubiese sido para la economía, habría sin duda lesionado los intereses (...). (CORPES XXI).

\subsection{Verbos de la apódosis}

Si los cinco tiempos anteriores participan en oraciones concesivas en los que se usan conectores no ambiguos en cuanto a la factualidad (v. ap. 4.1), el valor de certeza de dichas frases no podrá ser asignado. Para determinar el valor factual de estos cinco casos se han analizado el conector y el tiempo verbal de la apódosis, con el fin de comprobar si este puede determinar el valor factual de la concesiva.

Por un lado, en el caso del condicional simple el análisis de estos dos elementos no ha permitido desambiguar su carácter factual. Ahora bien, parece que el análisis de la referencia temporal del verbo que se presenta en la oración principal permitiría determinar el valor factual de la concesiva. Así en (30a), donde esta referencia es del pasado, la concesiva tiene un valor factual, mientras que en (30b), donde se proyecta una situación futura (un deseo), la concesiva es "no aplica". No obstante, en este trabajo no hemos llegado a determinar si esta regla es susceptible de ser generalizada.

(30)

a. El primer ministro anuló los actos de campaña (...), aunque mantendría su reunión (...). (CORPES XXI).

b. El líder del PSOE quiere elecciones, aunque los barones se abstendrian (...). (CORPES XXI).

Con el condicional compuesto en la prótasis, si el conector es si bien o pese a (que) y en la apódosis encontramos también condicional compuesto, la concesiva será no factual (31). 
(31) Trasladó, asimismo, que, de la versión ofrecida por el adolescente, se desprendía que él mismo habría prendido fuego a el sillón con un mechero u objeto similar, si bien habría intentado sofocar lo posteriormente (Corpus del Español).

En cuanto al presente de subjuntivo, este por defecto será factual, pero si aparece con por mucho que y en la apódosis encontramos condicional simple, la concesiva será "no aplica" (32). Parecido sucede con pluscuamperfecto de subjuntivo, tiempo contrafactual por defecto; no obstante, si en la apódosis encontramos imperfecto de indicativo, el valor pasa a ser factual (29a).

(32) Por mucho que se trague sapos y llegue a un acuerdo con Podemos (...), le haría falta el apoyo de lo que queda de IU (...). (CORPES XXI).

Por último, el imperfecto de subjuntivo puede ser contrafactual o "no aplica" en función del conector siempre que en la apódosis identifiquemos el uso del condicional simple. Si el conector es aunque, la concesiva será contrafactual (33a). Si, en cambio, es aun cuando o por más que, la concesiva será "no aplica" (33b).

(33)

a. Marco Antonio Pinochet, aseguró que su padre «es inocente de lo que se le acusa» y que, "aunque fuera culpable y no lo es», la familia seguiría a su lado. (CORPES XXI).

b. Además, aun cuando estuviera disponible este entronque, persistiría el problema de quienes se desplazan desde el Nalón (...). (CORPES XXI).

\subsection{Reglas de formación}

Las reglas que presentamos en este apartado son una propuesta de formalización para la anotación automática de la factualidad de las oraciones concesivas a partir de tres marcadores lingüísticos: los conectores, los tiempos verbales de las prótasis y de las apódosis. La propuesta de aplicación de las reglas se presenta ordenada en bloques, ya que hay veces que la anotación se puede resolver directamente identificando el conector, mientras que para otros conectores es necesario identificar el tiempo de la prótasis e incluso de la apódosis.

Antes de pasar a especificar dichas reglas vamos a comentar algunas cuestiones que tienen que ver con la utilización de estos patrones en un sistema automático de anotación de factualidad. En cuanto a los conectores, en definitiva, son cadenas léxicas formadas por dos o más elementos que prevemos que el sistema podrá identificar sin problemas, ya que no son polisémicas y, por tanto, siempre se usan en oraciones concesivas.

Por lo que se refiere a los tiempos verbales, cabe decir que el sistema de anotación automático que estamos elaborando en el proyecto actuará sobre un texto ya anotado 
morfológicamente. Concretamente, se ha utilizado Freeling, un analizador y desambiguador morfológico, para anotar las palabras de los textos procesados con sus categorías morfosintácticas. Así pues, partiremos de un texto en el cual estarán anotados los verbos de las oraciones con su tiempo verbal. En nuestras reglas se ha especificado los distintos tiempos verbales posibles en las prótasis y las apódosis de las oraciones concesivas con estas etiquetas para guiar el análisis. Cabe decir que el texto también se habrá anotado previamente aplicando un análisis sintáctico de dependencias, también de Freeling. Esta tarea es clave en la propuesta de formalización presentada ya que previsiblemente va a permitir identificar los límites de la prótasis y de la apódosis en las oraciones concesivas. Del éxito de este análisis sintáctico, va a depender el éxito de las reglas que aquí proponemos para la anotación de la factualidad en el caso de algunas oraciones. La identificación automática de la apódosis es la que se prevé más complicada y las posibles subordinaciones dentro de cada cláusula también van a ser un escollo.

En todo caso, hemos previsto posibles soluciones en el caso de que finalmente se considere que el análisis de dependencias obtenido de forma automática no sea satisfactorio y no se pueda utilizar para aplicar las reglas presentadas en este estudio. Por un lado, hemos observado ciertas tendencias en el corpus de concesivas analizado que nos hacen pensar que la identificación del verbo de la prótasis, al menos, previsiblemente va a ser factible en la mayoría de las oraciones. En primer lugar, tras el conector, independientemente de cuál sea este, se encuentra mayoritariamente el verbo de la prótasis, si bien puede haber un intervalo de dos o tres palabras entre conector y verbo (29a). En segundo lugar, en el caso de las formas no finitas, estas se sitúan en todos los casos inmediatamente después del conector y sin posibilidad de separación $(24,25)$.

Por otro lado, para la identificación del verbo de la apódosis se han observado ciertas tendencias en el orden de las dos cláusulas que pueden ayudar si el análisis de la herramienta Freeling finalmente no puede ser tenido en cuenta. Así, con aun + gerundio (25) y con por mucho que (32), la prótasis se encuentra en posición antepuesta con respecto a la apódosis en más del 70\% de los casos. En cuanto a aunque (33), si bien (31), por más que (28a), aun a riesgo de (que) (18b) y aun a sabiendas de (que) (18a), la prótasis ocupa la segundo posición en más del 69\% de los casos. Con aun cuando (33b), a pesar de (que) (24a), por muy + adjetivo + que (29c) y con pese a (que) (22c), no hay una posición más frecuente que la otra, por lo que se iniciará la búsqueda de forma aleatoria. En cualquiera de los casos, si la búsqueda es fallida, se realizará también en la dirección contraria. ${ }^{4}$ Por último, en la identificación del verbo de la apódosis (pero también en el de la prótasis), va a ser crucial especificar la búsqueda a partir de los tiempos posibles en estas cláusulas. En el caso de las apódosis, por ejemplo, quedan descartados como candidatos todas las formas no finitas y los tiempos de subjuntivo.

\footnotetext{
${ }^{4}$ Obviamente, antes de dirigir la búsqueda del verbo de la apódosis habrá que tener en cuenta las pistas que nos dé la puntuación: si el conector de la concesiva está situado después de un punto o punto y coma, el verbo de la apódosis se buscará a la derecha de la limitación de la cláusula subordinada. En caso de que el límite de la cláusula concesiva coincida con un punto o punto y coma, el verbo de la apódosis se buscará a la izquierda del conector.
} 
En cualquier caso, la cuestión de la implementación de las reglas presentadas en este artículo deberá abordarse en trabajos posteriores. Así pues, a continuación, nos centraremos en describir nuestra propuesta de formalización para anotar la factualidad de las oraciones concesivas teniendo en cuenta su esqueleto básico de conectores y tiempos verbales en la prótasis y la apódosis, que es el objetivo de este artículo. En esta propuesta los casos para los cuales no se llega determinar el valor exacto de factualidad solo afectan a un tiempo verbal específico en la prótasis: el condicional. Con estos resultados, consideramos que podemos validar nuestra hipótesis inicial, según la cual es posible formalizar la factualidad en las oraciones concesivas del español usando marcadores lingüísticos.

Las etiquetas que se usan en Freeling para cada tiempo están indicadas en las tablas, que incluyen la propuesta de formalización. La cursiva se utiliza para indicar el conector y la etiqueta de factualidad se presenta entre paréntesis angulares.

El sistema de anotación automático del proyecto actuará sobre un texto ya anotado morfológicamente. Concretamente, se ha utilizado Freeling, un analizador y desambiguador morfológico, para anotar las palabras del corpus TAGFACT con sus categorías morfosintácticas. Así pues, partimos de un texto en el cual estarán anotados los verbos de las oraciones con su tiempo verbal. Además, también se ha aplicado un análisis sintáctico de dependencias con el analizar sintáctico de Freeling para identificar el alcance de la predicación, por lo que las oraciones subordinadas están identificadas.

Por otra parte, hemos observado que, en las oraciones del estudio, tras el conector, independientemente de cuál sea este, se encuentra mayoritariamente el verbo de la prótasis, si bien puede haber un intervalo de dos o tres palabras entre conector y verbo (33b). En el caso de las formas no finitas, estas se sitúan en todos los casos inmediatamente después del conector y sin posibilidad de separación (30, 33a).

Teniendo en cuenta lo expuesto, seguidamente, vamos a detallar paso a paso cómo determinaríamos el valor de factualidad para el verbo núcleo de una concesiva. Hay que aclarar que el valor se asocia al verbo, pero alcanza toda la frase de la oración subordinada.

\section{Conectores:}

Cuando la oración concesiva es introducida por uno de los conectores del cuadro 6 , el valor factual de la construcción podrá ser asignado al primer verbo situado a la derecha de este. Como puede observarse, en algunos casos se requiere un tiempo verbal específico para ese conector. Cada regla aparece numerada al final de la tabla. En el Anexo 1 se presenta un ejemplo representativo de cada una de ellas. 
Cuadro 6. Conectores con valor factual

\begin{tabular}{|c|c|c|c|}
\hline Conector & Tiempo verbal de la prótasis & Valor & No \\
\hline \multirow{3}{*}{ a pesar de (que) } & Condicional compuesto (VAIC) & [Contrafactual] & 1 \\
\hline & Futuro (VMIF) & [No factual $]$ & 2 \\
\hline & Cualquier otro tiempo verbal & {$[$ Factual $]$} & 3 \\
\hline aun & $\begin{array}{l}\text { Gerundio simple (VMG) y gerundio } \\
\text { compuesto (VMG VMP) }\end{array}$ & [Factual $]$ & 4 \\
\hline aun a riesgo de (que) & Cualquier tiempo verbal & [No aplica] & 5 \\
\hline \multirow{2}{*}{ aun a sabiendas de (que) } & Futuro (VMIF) & [No factual] & 6 \\
\hline & Cualquier otro tiempo verbal & [Factual $]$ & 7 \\
\hline pese a (que) & $\begin{array}{l}\text { Cualquier tiempo verbal excepto } \\
\text { condicional compuesto (VAIC) }\end{array}$ & {$[$ Factual $]$} & 8 \\
\hline \multirow[t]{2}{*}{ por muy [ADJ] que } & $\begin{array}{l}\text { Pretérito pluscuamperfecto de subjuntivo } \\
\text { (VASI VMP) }\end{array}$ & [No aplica] & 9 \\
\hline & Cualquier otro tiempo verbal & {$[$ Factual $]$} & 10 \\
\hline \multirow{2}{*}{ sibien } & Futuro (VMIF) & [No factual] & 11 \\
\hline & $\begin{array}{l}\text { Cualquier otro tiempo verbal excepto } \\
\text { condicional compuesto (VAIC) }\end{array}$ & [Factual] & 12 \\
\hline
\end{tabular}

2. Tiempos verbales de la prótasis

Las reglas de este bloque solo se aplicarán a las concesivas introducidas por conectores no previstos en el cuadro 6 y que son los siguientes:

- aunque

- aun cuando

- por más que

- por mucho que

En los casos que ahora presentamos el conector no puede ayudar a determinar la factualidad por lo que se considerará directamente el tiempo del verbo de la prótasis. Concretamente, las formas finitas y no finitas que determinan el valor factual de la oración concesiva en estos casos son los que se mencionan en el cuadro 7. 
Cuadro 7. Valores factuales y etiquetas del anotador de los tiempos verbales concluyentes

\begin{tabular}{|c|c|c|c|}
\hline Valor factual & Formas finitas & Formas no finitas & No \\
\hline [Factual] & $\begin{array}{c}\text { Presente de indicativo (VMIP) } \\
\text { Pretérito imperfecto de indicativo (VMII) } \\
\text { Pretérito perfecto simple de indicativo } \\
\text { (VMIS VMP) } \\
\text { Pretérito perfecto compuesto de indicativo } \\
\text { (VAIS VMP) } \\
\text { Pretérito pluscuamperfecto de indicativo } \\
\text { (VAII VMP) } \\
\text { Pretérito perfecto de subjuntivo } \\
\text { (VASIS VMP) }\end{array}$ & $\begin{array}{c}\text { Infinitivo (VMN) } \\
\text { Infinitivo compuesto } \\
\text { (VMN VMP) } \\
\text { Participio (VMP) }\end{array}$ & 13 \\
\hline [No factual] & Futuro (VMIF) & & 14 \\
\hline
\end{tabular}

En el siguiente cuadro (cuadro 8), se presentan las etiquetas por defecto que se le asignarán a los tiempos verbales no presentados en el cuadro 7, es decir, al condicional simple y al compuesto, así como al presente, imperfecto y pluscuamperfecto de subjuntivo. Aquellos valores que aparecen en el cuadro junto con un asterisco $\left(^{*}\right)$, si bien presentan un valor por defecto, cuentan con excepciones según el análisis realizado de nuestro corpus, lo que provoca un cambio en su carácter factual. Dichas excepciones serán descritas en la siguiente sección.

Cuadro 8. Valores factuales y etiquetas por defecto de los tiempos verbales no concluyentes

\begin{tabular}{|c|c|c|c|}
\hline Conector & Tiempo verbal prótasis & Valor factual prótasis & $N^{\mathbf{a}}$ \\
\hline & Condicional simple (VMIC) & {$[$ No aplica] / [Factual] } & 15,16 \\
\hline & Condicional compuesto (VAIC) & {$\left[\right.$ No aplica] ${ }^{*}$} & 17 \\
\hline aun cuando & Presente subjuntivo (VMSP) & {$\left[\right.$ Factual] ${ }^{*}$} & 18 \\
\hline & Presente subjuntivo (VMSP) & {$[$ No aplica] / [[Factual] } & 19 \\
\hline & $\begin{array}{c}\text { Pretérito imperfecto subjuntivo (VMSI) } \\
\text { (VASI VMP) }\end{array}$ & {$\left[\right.$ Factual] ${ }^{*}$} & 20 \\
\hline
\end{tabular}


3. Tiempos verbales de la apódosis

Para solucionar el valor factual de las formas verbales expuestas en el cuadro anterior (cuadro 8) acompañadas de asterisco, se procede a analizar el tiempo verbal de la apódosis. Es el caso de prótasis con:

- Condicional compuesto (VAIC)

- Presente de subjuntivo (VMSP) (con un conector distinto a aun cuando)

- Pretérito imperfecto de subjuntivo (VMSI)

- Pretérito pluscuamperfecto de subjuntivo (VASI VMP)

Para poder determinar qué valor es el adecuado en cada oración se debe proceder a identificar el tiempo verbal de la apódosis y comprobar si es alguno de los que aparecen en la casilla marcada en gris en el cuadro 9. Si el tiempo no es coincidente, se le aplicaría el valor por defecto que aparece en dicho cuadro y no habrá que hacer más comprobaciones. Si es coincidente, en algunos casos habrá que comprobar si aparece una determinada conjunción y, si es así, se aplicará el valor específico; si no, también se aplicará el valor por defecto. Por ejemplo, si en la prótasis se usa un verbo presente de subjuntivo, puede recibir dos etiquetas:

- Si el verbo de la apódosis no es condicional simple: [Factual].

- Si el verbo de la apódosis es condicional simple:

- y la conjunción no es por mucho que: [Factual]

- y la conjunción es por mucho que: [No aplica].

Cuadro 9. Etiquetas de los tiempos verbales con más de un valor factual

\begin{tabular}{|c|c|c|c|c|c|}
\hline $\begin{array}{l}\text { Tiempo verbal } \\
\text { protasi }\end{array}$ & $\begin{array}{l}\text { Valor por } \\
\text { defecto }\end{array}$ & No & \multicolumn{2}{|c|}{ Excepcione } & No \\
\hline \multirow{3}{*}{$\begin{array}{l}\text { Condicional } \\
\text { compuesto }\end{array}$} & \multirow{3}{*}[\mathrm{NA}]{} & \multirow{3}{*}{22} & \multicolumn{2}{|c|}{ [No factual] } & \\
\hline & & & Conjunción & Tiempo verbal apódosis & \\
\hline & & & $\begin{array}{c}\text { si bien } \\
\text { pese a que }\end{array}$ & Condicional compuesto & 23 \\
\hline \multirow{3}{*}{$\begin{array}{c}\text { Presente } \\
\text { subjuntivo }\end{array}$} & \multirow{3}{*}{ [Factual] } & \multirow{3}{*}{24} & \multicolumn{2}{|c|}{ [No aplica] } & \\
\hline & & & Conjunción & Tiempo verbal apódosis & \\
\hline & & & por mucho que & Condicional simple & 25 \\
\hline
\end{tabular}




\begin{tabular}{|c|c|c|c|c|c|c|c|}
\hline \multirow{3}{*}{$\begin{array}{c}\text { Pretérito } \\
\text { imperfecto } \\
\text { subjuntivo }\end{array}$} & \multirow{3}{*}{ [Factual] } & \multirow{3}{*}{26} & \multicolumn{2}{|c|}{ [No aplica] } & \multicolumn{2}{|c|}{ [Contrafactual] } & \\
\hline & & & Conjunción & $\begin{array}{c}\text { Tiempo } \\
\text { verbal } \\
\text { apódosis }\end{array}$ & Conjunción & $\begin{array}{c}\text { Tiempo } \\
\text { verbal } \\
\text { apódosis }\end{array}$ & \\
\hline & & & $\begin{array}{l}\text { aun cuando } \\
\text { por más que }\end{array}$ & $\begin{array}{l}\text { Condicional } \\
\text { Simple }\end{array}$ & Aunque & $\begin{array}{l}\text { Condicional } \\
\text { Simple }\end{array}$ & $\begin{array}{l}27, \\
28, \\
29\end{array}$ \\
\hline \multirow{3}{*}{$\begin{array}{c}\text { Pretérito } \\
\text { pluscuamperfecto } \\
\text { subjuntivo }\end{array}$} & \multirow{3}{*}{ [Contrafactual] } & \multirow{3}{*}{30} & \multicolumn{4}{|c|}{ [Factual] } & \\
\hline & & & \multirow{2}{*}{\multicolumn{2}{|c|}{ Conjunción }} & \multicolumn{2}{|c|}{ Tiempo verbal apódosis } & \\
\hline & & & & & \multicolumn{2}{|c|}{ Imperfecto indicativo } & 31 \\
\hline
\end{tabular}

Después de lo expuesto, concluimos que nos quedaría solo el condicional simple como tiempo verbal no concluyente, ya que, partiendo de los datos de nuestro corpus, este tiempo puede presentar varios valores y no se ha detectado ninguna pista formal que nos permita determinar cuándo expresa uno u otro valor.

\section{CONCLUSIONES}

En este trabajo hemos analizado 973 oraciones concesivas del español extraídas de corpus periodísticos. Por un lado, el estudio realizado nos ha permitido confirmar en gran medida lo señalado por los autores respecto a la expresión de la factualidad en las concesivas en español, aunque se han ampliado los valores asociados para algunos tiempos verbales y conectores. Por otro lado, se han diseñado reglas basadas en marcadores lingüísticos validando así la hipótesis de partida. Estas reglas son susceptibles de ser incorporadas en un sistema de anotación de factualidad automático.

Los marcadores utilizados han sido los conectores y los tiempos verbales. En cuanto a los primeros, de los 10 estudiados hemos visto que solo 1 puede ser asociado directamente a un solo valor factual y que el resto presentan diferentes opciones. Para estos conectores, se ha utilizado otro marcador que determina la factualidad de una concesiva, que es la forma verbal de la prótasis. De todas las 13 formas verbales que hemos identificado en las prótasis de las oraciones del corpus estudiado, solo hay 6 que presentan más de un valor, es decir, son no concluyentes. Es el caso del condicional simple y compuesto, el presente de subjuntivo, el pretérito imperfecto de subjuntivo y el pluscuamperfecto de subjuntivo.

El tercer marcador es el tiempo verbal de la apódosis. A este marcador se recurre únicamente en aquellos casos que se mantienen no concluyentes después de analizar los otros dos marcadores. El resultado final es que las reglas propuestas permiten determinar la 
factualidad de todas las prótasis concesivas, sea cual sea el conector, excepto aquellas en que esa oración contiene el tiempo condicional simple. No descartamos que puedan existir otros elementos que permitirían resolver esta cuestión, que queda pendiente como trabajo futuro.

También pretendemos ampliar el número de frases utilizado para el análisis, ya que para la combinación de determinados conectores con determinados tiempos sería apropiado obtener más ejemplos. Una vez analizados podría ser necesario modificar algunas de las reglas, aunque creemos que los cambios, si los hubiera, serían menores.

Otra tarea pendiente es la implementación de las reglas propuestas para comprobar su grado de éxito en un sistema automático, tanto con las oraciones del estudio como con otras. Aunque hemos previsto algunas soluciones para posibles fallos del análisis de dependencias que se usará para etiquetar los textos, hay otros de peor solución que será necesario explorar, como el caso de las oraciones con mucha subordinación, ya que puede resultar que el sistema tome como verbos núcleos de las cláusulas algunos que no lo son. Otro problema que hemos identificado es el caso de prótasis que se sitúan insertadas entre elementos de la principal, lo que provoca que localizar automáticamente el verbo principal de la apódosis resulte complejo. También es posible que el conector concesivo se encuentre tras un punto y que, a su vez, haga referencia al evento de la oración anterior, es decir, puede haber casos en los que la oración concesiva esté disgregada de la principal con la puntuación. Esto último sería un problema solo en la fase de búsqueda del verbo de la apódosis. En cualquier caso, como la identificación de los verbos de las apódosis no es tan relevante en nuestra propuesta, los problemas relacionados con esta tarea específica no tendrán tanta repercusión como los relacionados con las prótasis, que, por otro lado, se prevén menores.

\section{OBRAS CITADAS}

Ahern, Aoife. 2008. El subjuntivo: contextos y efectos. Madrid: Arco/Libros.

Alarcos Llorach, Emilio. 1994. Gramática de la lengua española. Madrid: Real Academia Española. Colección Nebrija y Bello.

Alonso, Laura, Irene Castellón Masalles, Hortènsia Curell i Gotor, Ana María Fernández Montraveta, Sònia Oliver del Olmo \& Glòria Vázquez García. 2018. Proyecto TAGFACT: Del texto al conocimiento. Factualidad y grados de certeza en español. Procesamiento del Lenguaje Natural, 61: 151-154.

Borrego, Jesús, José J. Gómez Asensio \& Emilio Prieto de los Mozos. 1985. El subjuntivo. Valores y usos. Madrid: Sociedad General Española de Librería.

Cortés Parazuelos, María Helena. 1993. “"Bipolares” al servicio de la "concesividad”: causales, condicionales y adversativas". Verba 20. 221-254.

Cortés Parazuelos, María Helena. 2002. La expresión de la concesividad en español. Tesis, Madrid: Universidad Complutense de Madrid.

Davies, Mark. 2018. Corpus del español. <https://www.corpusdelespanol.org/x.asp>

Diab, Mona. T., Lori Levin, Teruko Mitamura, Owen Rambow, Vinodkumar Prabhakaran 
\& Weiwei Guo. 2009. "Committed belief annotation and tagging”. Proceedings of the Third Linguistic Annotation Workshop ACL-IJCNLP. Suntec: Singapore. 68-73.

Fernández Montraveta, Ana María, Hortènsia Curell i Gotor, Glòria Vázquez García \& Irene Castellón Masalles. 2020. The TAGFACT annotator and editor: A versatile tool. Research in Corpus Linguistics, vol. 8, núm. 1, p. 131-146.

Flamenco García, Luis. 1999. "Las construcciones concesivas y adversativas”. En Bosque, Ignacio y Demonte, Violeta (Eds.), Gramática descriptiva de la lengua española, 3 vols. Madrid: Espasa-Calpe. 3805-3878.

Gili y Gaya, Samuel. 1961. Curso superior de sintaxis de la lengua española. Barcelona: Bibliografía.

König, Ekkehard. 1986. "Conditionals, concessive conditionals and concessives: areas of contrast, overlap and neutralization”. En Elizabeth C. Traugott, Alice ter Meulen, Judith S. Reilly, y Charles A. Ferguson (Eds.), On conditionals. Cambridge: Cambridge University Press. 229-246.

Minard, Anne-Lyse, Manuela Speranza, Ruben Urizar, Begoña Altuna, Marieke Van Erp, Anneleen Schoen \& Chantal Van Son. 2016. MEANTIME, the NewsReader multilingual event and time corpus. En Proceedings of the Tenth International Conference on Language Resources and Evaluation (LREC'16), 4417-4422.

Padró, Lluis \& Evgeny Stanilovsky. 2012. FreeLing 3.0: Towards Wider Multilinguality. En International Conference on Language Resources and Evaluation (LREC2012). Estambul. 2473-2479.

Pérez Saldanya, Manuel \& Vicent Salvador. 2015. “Oraciones concesivas”. En Company, Concepción. (dir.), Sintaxis Histórica de la Lengua Española, 3 vols. México: Universidad Nacional Autónoma de México. 3699-3839.

Real Academia de la Lengua Española. 1973. "Subordinadas circunstanciales II". Esbozo de una Nueva Gramática de la Lengua Española. Madrid: Espasa-Calpe. 557-559.

Real Academia de la Lengua Española. 2010. “Oraciones condicionales y concesivas”. Nueva Gramática de la lengua española. Madrid: Espasa Libros. 915-922.

Real Academia Española: Banco de datos. 2019. (CORPES) [en línea]. Corpus del español del siglo XXI. <http://www.rae.es>

Real Academia Española: Banco de datos. 2019. (CREA) [en línea]. Corpus de referencia del español actual. <http://www.rae.es>

Rivarola, J, L. 1976. "Las conjunciones concesivas en español medieval y clásico”. Tubinga, Max Niemeyer.

Rivas, Elena. 1990. "A propósito de condicionales y concesivas reales. Referencias diacrónicas en torno a estas últimas". Verba 17. 159-169.

Rodríguez Rosique, Susana. 2008. Pragmática y Gramática: condicionales concesivas en espanol. Frankfurt am Main: Peter Lang.

Rojo, Guillermo. 1974. "La temporalidad verbal en español”. Verba 1. 68-149.

Sastre, María Ángeles. 2004. El subjuntivo en español. Los Libros del Español. Español lengua extranjera. Colegio de España. 
Saurí, Roser. 2008. A factuality profiler for eventualities in text. Tesis. Waltham: Brandeis University.

Saurí, Roser \& James Pustejovsky. 2009. "FactBank: a corpus annotated with event factuality." Language resources and evaluation 43.3: 227.

Vallejo, César. 1922. "Notas sobre la expresión concesiva". Revista de Filología Española. 40-51.

Vázquez García, Glòria \& Ana María Fernández Montraveta. 2020. "Annotating factuality in the TAGFACT corpus." Multiperspectives in Analysis and corpus design. Miguel Fuster-Márquez, Carmen Gregori-Signes, José Santaemilia Ruiz (Eds). Granada: Comares.

Wonsever, Dina, Marisa Malcuori \& Aila Rosá. 2009. Factividad de los eventos referidos en textos. Reporte técnico RT 09-12. PEDECIBA informática. Uruguay: Universidad de la República.

Wonsever, Dina, Aiala Rosá \& Marisa Malcuori. 2016. "Factuality annotation and learning in Spanish texts." Proceedings of the Tenth International Conference on Language Resources and Evaluation (LREC'16). 


\section{ANEXo}

1. La Fiscalía aún no ha formulado ninguna acusación contra' El Pastelero' y' Costiña', a pesar de que habría tenido la oportunidad de que se les juzgase en la primera semana de enero, cuando la Audiencia Nacional sentó en el banquillo a un nuevo imputado por la’ operación Destello’, Germán Gonzalo Sánchez Rey,' El Compa’ o’ El Coletas'. (Corpus del Español).

2. El presidente del cartel y ministro argelino de Energía, Chakib Khelil, declaró que, a pesar de que la cifra definitiva se decidirá hoy, le parecía 'excelente' esa reducción. (CORPES XXI).

3. Compareció el subdelegado del Gobierno en Guadalajara, Juan Pablo Herranz, quien aseguró que la alerta 2 funcióno «desde el primer momento», puesto que desde el inicio hubo medios ajenos a la Junta castellano-manchega, a pesar de que el único hidroavión aportado por el Ministerio de Medio Ambiente se averió. (CORPES XXI).

4. Así, el PSOE y el PSN inciden en que Barcina se está escudando en que los socialistas no quieren hacer política con Bildu para mantenerse en el cargo, aun sabiendo el «daño» que está haciendo a la comunidad. (CORPES XXI).

5. El rey Juan Carlos ha hecho todo lo posible por permanecer en la sombra, aun a riesgo deque las noticias sobre sus actividades acabaran reducidas a sus escapadas gastronómicas o sus excursiones a destinos lejanos. (Corpus del Español).

6. La oposición suma sus votos para forzar la convocatoria de un pleno en el que comparezca el ministro de Economía por el' caso Soria' aun a sabiendas de que el Gobierno se negará. (Corpus del Español).

7. A dos años de las elecciones municipales de 2019, y aun a sabiendas de que en política son toda una eternidad, en el PP ha comenzado a abrirse el debate de cuándo afrontar la designación de los candidatos de las principales ciudades. (Corpus del Español).

8. Chávez, como expresó su vicepresidente, no confía en que la oposición tenga capacidad para recoger las firmas necesarias para convocar el referéndum, según lo establece la Constitución -al menos el 15 por ciento de los votantes inscritos en el registro electoral-, pese a que la Coordinadora Democrática, que engloba a los principales sectores disidentes, logró cuatro millones de firmas el pasado mes de febrero. (CORPES XXI).

9. En el caso español, cualquier "pinchazo" preventivo de la burbuja, por muy saludable que hubiese sido para la economía, habría sin duda lesionado los intereses del sector financiero y hubiese forzado al BE a enfrentarse abiertamente con él. (CORPES XXI).

10. "Una cosa son las declaraciones de un ministro, por muy importante que sea, y otra cosa son las decisiones, que en materia de retribuciones de los trabajadores se toma afortunadamente en los convenios colectivos", recalcó Toxo. (CORPES XXI).

11. El 29 de marzo el secretario general de Podemos, Pablo Iglesias, declaraba en una entrevista en la Cadena Ser que la formación defendería la celebración de un referéndum en Cataluña, si bien "no será específicamente un referéndum de independencia”, sino 
uno en que "todas las opciones sean posibles" y que "no tiene por qué contener sólo dos opciones". (Corpus del Español).

12. $\underline{\mathrm{Si} \text { bien }}$ ambos trabajos llegaron a una conclusión similar respecto a la concepción del votante, considerando que los electores partían de unas predisposiciones que determinaban su voto, presentan ciertas diferencias. (CORPES XXI).

13. Aunque la negociación final fue en Bruselas, el ok político desde Osaka fue imprescindible para oficializar una «asociación estratégica» entre dos bloques que suman el 20\% del PIB mundial y comercian bienes y servicios por unos 90.000 millones de euros. (Corpus del Español).

14. Entre ellas, la del eurodiputado Javier Nart, que, aunque deja la Ejecutiva mantendrá su escaño en Bruselas. (Corpus del Español).

15. El primer ministro anuló los actos de campaña tras el ataque a una parlamentaria laborista, aunque mantendría su reunión con el ministro principal del Peñón, Fabián Picardo, que le ha recibido en el aeropuerto. (CORPES XXI).

16. Aunque la moratoria afectaría a planes en marcha para la construcción de 150,000 viviendas, las recomendaciones del Eurocámara resultan sensatas. (CORPES XXI).

17. El imputado sí admitió que se firmaron peonadas falsas para acceder al subsidio agrario a varias personas, aunque habría responsabilizado de ello a los delegados municipales de Personal y de Campo (Corpus del Español).

18. $\mathrm{Y}$ aunque se hallen próximos a los morados en cuestiones sociales, hay asuntos de Estado o temas extremadamente sensibles como Cataluña que les distancian. (Corpus del Español).

19. Los ministros y los parlamentarios no tienen contrato laboral de manera que, aun cuando quieran secundar una huelga, no se les descuenta la parte del salario correspondiente al tiempo no trabajado (Corpus del Español).

20. Este tipo de moción, puramente simbólica, se tendrá que votar en una fecha que fijará el propio Gobierno. Con ella, el laborismo pretende erosionar aún más el liderazgo y la autoridad de la primera ministra. De esta forma, ni el Ejecutivo ni el puesto de May corren peligro, aunque fuera aprobada. (Corpus del Español).

21. Colaboradores y rivales insisten en que la nueva presidenta representa un "cambio de formas" significativo. "Aunque hubiera tenido mayoría absoluta, habría planteado pactos a la oposición. El rodillo se ha acabado. Los votantes quieren cambios y ella es de otra generación”, asegura un miembro de su equipo. (Corpus del Español).

22. El dirigente italiano se reunió en un primer momento con su agente, Mino Raiola, y posteriormente con el propio delantero, que, aunque habría respondido afirmativamente a la propuesta de volver a San Siro, habría remitido a su club para continuar con las negociaciones. (Corpus del Español).

23. Según el sondeo a pie de urna coordinado por BBC, ITV y Sky News, el Partido Conservador se haría con la victoria en los comicios, si bien habría perdido la mayoría absoluta, ya que se quedaría con 314 de los 650 escaños que componen el Parlamento. (Corpus del Español). 
24. La posibilidad de proponer un nuevo Estatuto ha sido apuntada en algunos medios como una actitud de Zapatero para obtener el apoyo parlamentario del PNV en su investidura, pero él reiteró que eso no forma parte de su "agenda de colaboración parlamentaria”, por más que esté abierto al diálogo con los nacionalistas. (CORPES XXI).

25. Por mucho quese trague sapos y lleguea un acuerdo con Podemos-de quien aparentemente tampoco le separan tantas cosas, a tenor de lo oído en la campańa electoral- le haría falta el apoyo de lo que queda de IU, de alguien más -tal vez ERC- y la abstención de un quinto grupo. (CORPES XXI).

26. Así, Iglesias está decidido a sentarse con el líder del PSOE sólo para un Ejecutivo de coalición, por mucho que Carmen Calvo y José Luis Ábalos dejaran este lunes la puerta abierta a "un Ejecutivo en solitario". (Corpus del Español).

27. Ante la convocatoria de elecciones, la actitud de Rajoy fue "de escucha, atención, de respuesta" aun cuando la respuesta no fuera satisfactoria los días 2525 a 27 de octubre. (Corpus del Español).

28. En tres meses, por más que edificaran y ganaran metros los colonos, el territorio palestino de Cisjordania no resultaría mucho más erosionado de lo que está ya. (CORPES XXI).

29. Aunque quisiera, Inma Iruretagoiena sería incapaz de ofrecer a los suyos una explicación de por qué otros vascos, como ellos mismos, odian hasta el punto de pretender matarlos. (CORPES XXI).

30. En su auto, Llarena explicaba que, aunque hubiera renunciado a su acta de diputada, eso "ni despeja la posibilidad de que persista la determinación para impulsar" el proceso soberanista, "ni excluye que los procesados puedan realizar aportaciones desde colaboraciones muy diversas y diferentes de la actividad parlamentaria". (Corpus del Español).

31. Schrems, que trabaja actualmente en su tesis doctoral y se dedica a dar conferencias sobre Facebook, denunció a la red social de Mark Zuckerberg en 2011, cuando descubrió que la plataforma guardaba los datos de los usuarios, aunque ellos los hubieran borrado. (Corpus del Español). 
